\title{
Postoperative pain pathophysiology and treatment strategies after CRS + HIPEC for peritoneal cancer
}

\author{
Xiao Wang and Tianzuo Li
}

\begin{abstract}
Background: Cytoreductive surgery (CRS) combined with hyperthermic intraperitoneal chemotherapy (HIPEC) is a treatment choice for peritoneal cancer. However, patients commonly suffer from severe postoperative pain. The pathophysiology of postoperative pain is considered to be from both nociceptive and neuropathic origins.

Main body: The recent advances on the etiology of postoperative pain after CRS + HIPEC treatment were described, and the treatment strategy and outcomes were summarized.

Conclusion: Conventional analgesics could provide short-term symptomatic relief. Thoracic epidural analgesia combined with opioids administration could be an effective treatment choice. In addition, a transversus abdominis plane block could also be an alternative option, although further studies should be performed.
\end{abstract}

Keywords: Peritoneal cancer, Pain, Nociceptive, Neuropathic, Cytoreductive surgery, Hyperthermic intraperitoneal chemotherapy, Analgesics

\section{Background}

Primary peritoneal cancer is a rare cancer that originates from the lining of the peritoneal cavity. Most peritoneal cancers are secondary to the dissemination of malignant cells from gastrointestinal or gynecological cancers [1]. Instead of being the terminal stage of cancer metastasis, secondary peritoneal cancer has been considered as a locoregional extension from the primary cancer [2]. The mainstay treatment for secondary peritoneal cancer is cytoreductive surgery (CRS) combined with hyperthermic intraperitoneal chemotherapy (HIPEC) [3-6]. Studies have revealed the improved survival rates of patients who received CRS + HIPEC treatment [7-9]. However, CRS + HIPEC treatment is a complex surgical procedure that commonly requires a long operation duration and causes significant surgical injuries. In addition, repeated

\section{* Correspondence: Itzbjsjtyy@163.com}

Department of Anesthesiology, Beijing Shijitan Hospital, Capital Medical University, No. 10 Tieyi Road, Yangfangdian, Haidian District, Beijing 100038, China

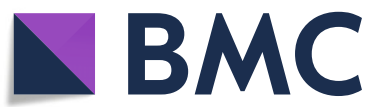

lavages in the peritoneal cavity with high-dose thermochemotherapeutic agents could exaggerate the stimulations and inflammations to the peritoneum. All these could contribute to the development of severe postoperative pain after surgery. Poorly managed postoperative pain could result in elevated stress and anxiety and further affect the quality of life of patients [10]. Due to the huge injury, patients with CRS and HIPEC have a high requirement for analgesia.

Our understanding on the development and treatment of postoperative pain after CRS + HIPEC treatment continues to evolve. The present study describes the recent advances on the etiology of postoperative pain after CRS + HIPEC treatment and summarizes the treatment strategy and outcomes.

\section{Main text}

Pathophysiology of postoperative pain

Acute postoperative pain after CRS + HIPEC treatment is different from the pain that occurs during a traditional

(c) The Author(s). 2020 Open Access This article is licensed under a Creative Commons Attribution 4.0 International License, which permits use, sharing, adaptation, distribution and reproduction in any medium or format, as long as you give appropriate credit to the original author(s) and the source, provide a link to the Creative Commons licence, and indicate if changes were made. The images or other third party material in this article are included in the article's Creative Commons licence, unless indicated otherwise in a credit line to the material. If material is not included in the article's Creative Commons licence and your intended use is not permitted by statutory regulation or exceeds the permitted use, you will need to obtain permission directly from the copyright holder. To view a copy of this licence, visit http://creativecommons.org/licenses/by/4.0/ The Creative Commons Public Domain Dedication waiver (http://creativecommons.org/publicdomain/zero/1.0/) applies to the data made available in this article, unless otherwise stated in a credit line to the data. 
abdominal surgery. CRS + HIPEC treatment not only causes nociceptive pain through surgical injuries and inflammation, but also induces neuropathic pain through simulations from the thermal chemotherapy (summarized in Table 1). Many factors can influence postoperative pain perception. These factors include preoperative baseline pain intensity; intraoperative injury from surgical incisions to the skin, muscle, nerves, and bones; postoperative inflammation; and abnormal ectopic neural activities from nerve damage. Mechanical injuries during the surgery and chemical and thermal injuries from the thermo-chemotherapy could cause nociceptive pain. Local inflammation responses at the site of injury could reduce the threshold of local nerve sensitivity, resulting in inflammatory pain [20]. Nerve injury could cause neuropathic pain [21]. All of these can interact with each other and promote peripheral and central pain sensitizations [22, 23].

\section{Nociceptive pain Inflammatory nociceptive pain}

Intense inflammatory responses have been reported during surgical operations. Both surgical injuries and subsequent infections could cause inflammatory nociceptive pain after CRS + HIPEC treatment. This is especially significant in patients with complications [11, 12]. High levels of serum danger-associated molecular patterns (DAMPs), tumor necrosis factor- $\alpha$ (TNF- $\alpha$ ), interleukin6 (IL-6), interleukin-8 (IL-8), and interleukin-10 (IL-10) have been identified in patients after CRS + HIPEC treatment. DAMPs could induce the local accumulation and activation of macrophages, which releases

Table 1 Pathophysiology of postoperative pain

\begin{tabular}{|c|c|c|}
\hline \multicolumn{3}{|l|}{ Nociceptive pain } \\
\hline \multirow[t]{2}{*}{$\begin{array}{l}\text { Inflammatory } \\
\text { nociceptive pain } \\
{[11,12]}\end{array}$} & $\begin{array}{l}\text { Peripheral } \\
\text { sensitization } \\
\text { [13] }\end{array}$ & $\begin{array}{l}\text { Prostaglandin } \mathrm{E}_{2} \text {, cytokines, nerve } \\
\text { growth factor, and substance P. } \\
\text { DAMPs, TNF-a, IL-6, IL-8, IL-10. }\end{array}$ \\
\hline & $\begin{array}{l}\text { Central } \\
\text { sensitization } \\
{[14]}\end{array}$ & $\begin{array}{l}\text { Microglia and inflammatory } \\
\text { factors }\end{array}$ \\
\hline \multicolumn{3}{|l|}{ Neuropathic pain } \\
\hline \multirow[t]{7}{*}{$\begin{array}{l}\text { Chemotherapeutic } \\
\text { agents }\end{array}$} & \multicolumn{2}{|c|}{$\begin{array}{l}\text { Mitochondrial dysfunction and } \\
\text { oxidative stress [15] }\end{array}$} \\
\hline & \multicolumn{2}{|c|}{ Increased calcium level } \\
\hline & \multicolumn{2}{|c|}{ Activation of glutamate receptor } \\
\hline & \multicolumn{2}{|c|}{ Activation of TRPV1 and TRPV4 [16] } \\
\hline & \multicolumn{2}{|c|}{$\begin{array}{l}\text { Increased expression of voltage-gated sodium } \\
\text { channels [17] }\end{array}$} \\
\hline & \multicolumn{2}{|c|}{$\begin{array}{l}\text { Aberrant expression of voltage-gated potassium } \\
\text { channels [18] }\end{array}$} \\
\hline & \multicolumn{2}{|c|}{ Neuroinflammation } \\
\hline Chronic pain & \multicolumn{2}{|c|}{$\begin{array}{l}\text { Nerve injury, excessive inflammatory response, } \\
\text { abnormal immune regulation [19] }\end{array}$} \\
\hline
\end{tabular}

interleukin-1 $\beta$ (IL-1 $\beta$ ), TNF- $\alpha$, and other proinflammatory cytokines. All these cytokines could affect peripheral and central pain sensitization $[11,12]$.

\section{Peripheral sensitization}

Peripheral pain sensitization has been reported during the postoperative stage [13]. Prostaglandin E2, cytokines, nerve growth factor, and substance $\mathrm{P}$ in the surgical incision site and serum can activate and sensitize peripheral pain receptors [24]. DAMPs and other pro-inflammatory cytokines can directly or indirectly act on the receptors of nociceptive neurons and activate a variety of complex signaling pathways, including protein kinase A, protein kinase $\mathrm{C}$, and $\mathrm{p} 38$ mitogen-activated protein kinase (MAPK). This could further reduce the peripheral neuronal excitation threshold and result in short-term peripheral sensitivity $[25,26]$.

\section{Central sensitization}

Central neuronal sensitization has been reported to be involved in postoperative hyperalgesia [14]. Proinflammatory cytokines, such as IL-1 $\beta$, IL- 6 , and TNF- $\alpha$, were maintained at low levels under normal situations. When surgical injury causes nerve damages, the microglia in the spinal cord and brainstem are activated by surface P2 receptors, chemokine receptors, and toll-like receptors (TLRs). The activated small microglia can release a series of inflammatory factors (IL-1 $\beta$, IL-6, and TNF- $\alpha$ ) that mediate neuroinflammatory responses, leading to central sensitization [27].

\section{Neuropathic pain}

Trauma, infection, cancer, and other conditions could cause neuropathic pain. This can be characterized as spontaneous pain, allodynia (pain response from nonnoxious stimulations), and hyperalgesia (excessive reactions from noxious stimulation) [28, 29]. Common histopathological and neurophysiological changes include neurodegeneration, loss of myelinated fibers, and the demyelination of myelinated fibers [30].

Morales-Soriano et al. analyzed the CRS + HIPEC procedure in 25 treatment centers for peritoneal cancer in Spain. The commonly used chemotherapeutic agents were platinum (cisplatin, oxaliplatin), taxanes (paclitaxel, docetaxel), and mitomycin [31]. Either the structure or the function of neurons and glial cells is changed by platinum-based chemotherapeutics [32]. There are various changes in the intracellular organelles (particularly mitochondria), membrane receptors, and ion channels, which are followed by changes in intracellular homeostasis, signaling, and neurotransmission. These alternations can lead to neuroinflammation, DNA damage, and axonal degeneration. Peripheral neuropathy is initiated by the accumulation 
of platinum-DNA adducts in dorsal root ganglion and trigeminal ganglion neurons, and this is probably the primary mechanism of neurotoxicity induced by platinum-based chemotherapeutics [33]. Taxanes cause the disruption of microtubules, which impairs axonal transport; leads to Wallerian degeneration; changes the activity of $\mathrm{Na}^{+}, \mathrm{K}^{+}$, and TRP ion channels; and induces the hyperexcitability of peripheral neurons. The mitochondrial damage promotes the production of reactive oxygen species, which damages the function of enzymes, and the structure of proteins and lipids. The disturbance of calcium homeostasis within neuronal cells causes the apoptosis and demyelination of peripheral nerves, which changes the excitability of peripheral neurons. The activation of glial cells induced by taxanes causes the activation of immune cells and the release and elevation of proinflammatory cytokines (interleukins and chemokines), which leads to nociceptor sensitization and the development of neuroinflammation [33-35].

Chemotherapeutic agents act on mitochondria, ion channels, and nerve structures and cause inflammation and severe NPP. Pain could persist during the entire treatment process of the chemotherapy and even last after the discontinuation of therapeutic agents [36].

\section{Mitochondrial dysfunction and oxidative stress}

Chemotherapeutic agents cause mitochondrial damage mainly through the destruction of the ATPasedependent sodium/potassium pump and disruptions in calcium balance. Paclitaxel can open the voltage-gated anion channels located in the outer membrane of mitochondria, leading to mitochondrial swelling and vacuolation. Oxaliplatin and other platinum-based agents can cause the attachment of platinum to mitochondrial DNA, resulting in decreased essential protein synthesis in mitochondria [37]. Mitochondrial dysfunction can induce oxidative stress, which plays an important role in the development of neuropathic pain [15]. Oxidative stress responses can release a large amount of oxidative products (oxygen-free radicals, syperoxynitroso, nitric oxide, etc.) to over-activate poly ADP-ribose polymerase (PARP). This further interferes with mitochondrial energy metabolism and exaggerates nerve damage. The expression of MAPK, NF- $\mathrm{kB}$, and activator protein 1 was elevated, which induces the synthesis of proinflammatory factors. All these participate in the development of peripheral sensitization [32].

\section{Calcium channel}

Chemotherapeutic agents can increase the expression of the DRG, calcium channel $\alpha 2-\delta 1$ subunit in the spinal cord dorsal horn neurons, sodium channel, and NMDA receptors. The activation of these receptors can lead to the influx of extracellular calcium and exudation of mitochondrial calcium. The increase in level of intracellular calcium can cause death in neurons through the production of oxygen free radicals and apoptosis. Calcium channels include voltage-gated calcium channels (VGCC), chemical channels (glutamate), and the transient receptor potential (TRP) family.

\section{Voltage-gated calcium channel}

Oxalate, a metabolite of oxaliplatin, can chelate with intracellular calcium to destroy the voltage-gated ion channel [38]. This could damage the peripheral nerves, but can be inhibited by a calcium channel antagonist [39].

\section{Glutamate}

Glutamate is an important excitatory neurotransmitter in the central nervous system. This can produce excitatory postsynaptic potentials by activating post-synaptic ionotropic glutamate receptors (NMDA receptors) in spinal dorsal horn neurons. The pain signal is transmitted to the advanced nerve center. The inflammatory reaction after tissue injury leads to the persistent activation of NMDA. The opening of the NMDA channel increases the influx of calcium, leading to central sensitization. Carozzi et al. reported the neuroprotective effect of oral glutamate carboxypeptidase inhibitors on peripheral neuropathy induced by three accepted animal models of chemotherapy (cisplatin, paclitaxel, and bortezomib) [40].

\section{TRP family}

TRP consists of seven subfamilies with 28 channels. Among these, TRPA1, TRPV1, and TRPV4 channels are mainly expressed in the DRG and trigeminal ganglion ganglia and are associated with NPP. TRPV1 is activated by high temperature $\left(\geq 43^{\circ} \mathrm{C}\right)$ and oxidative stress in mammalian cells, resulting in oxidative damage and hyperalgesia [41, 42]. When the temperature becomes higher than $24^{\circ} \mathrm{C}$, TRPV4 can also be activated [43]. The temperature used for HIPEC was $43^{\circ} \mathrm{C}$, which is the critical temperature for the irreversible damage of tumor cells [44]. During this process, the activation of TRPV1 and TRPV4 could occur, resulting in postoperative NPP. In the process of removing bacteria and viruses, ROS are produced by anti-inflammatory cells, such as macrophages and microglia [16]. There is a direct relationship between increased ROS levels and inflammatory pain. ROS could also directly activate TRPV1 to cause hyperalgesia [45]. Cisplatin and oxaliplatin induce TRAP1 activation by increasing the ROS level [46]. TRPV1 and TRPA1 have a synergistic effect to activate the DRG channel [47]. Paclitaxel could activate TRPV4 to induce the elevated levels of oxidative stress and mechanical 
pain. The intrathecal injection of TRPV4 can relieve the paclitaxel-induced mechanical hyperalgesia $[48,49]$.

\section{Sodium channel}

Studies have reported the increased expression of voltage-gated sodium channels (VGSCs) in ovarian and gastrointestinal cancers $[50,51]$. These cancers are the frequent causes of secondary peritoneal cancer. VGSCs play an important role in the production and conduction of action potentials at the terminal end of pain receptors and axons. Nine subtypes of VGSCs, NaV1.1-1.9, have been identified. Among these, subtypes NaV1.7, 1.8, and 1.9 have been considered to have a close relationship with the excitability of pain nociceptors [17]. Oxaliplatin could alter the functional properties of VGSCs, resulting in extended opening duration and the hyperexcitability of sensory neurons. Paclitaxel could increase the expression of VGSC subtype NAV1.7 in the DRG. The VGSC antagonist tetrodotoxin can alleviate the neuropathic pain caused by paclitaxel $[33,52]$.

\section{Potassium channel}

Voltage-gated potassium channels (VGKCs) include 12 subtypes and have aberrant expression levels in cancer tissues [18]. VGKCs are important regulators of neuronal excitability and play an important role in maintaining the membrane potentials [53]. These could control the action potential generation and regulate the release of neurotransmitters [54]. A previous study revealed that the decreased expression and activity of VGKCs is one of the causes of the peripheral sensitization of afferent nociceptive fibers and one of the major factors of persistent pain [55].

\section{Neuroinflammation}

Chemotherapy can cause significant pathological changes in the DRG, as well as in the surrounding peripheral neurons and satellite cells. After nerve injury, immune cells (mast cells, neutrophils, macrophages, Schwann cells, and $\mathrm{T}$ cells) are activated and release large amounts of inflammatory factors, including proinflammatory factors (IL-1 $\beta, \quad \mathrm{LL}-6$, and TNF- $\alpha$ ), chemokines (chemokine ligand 2, CCL2), inflammatory mediators (prostaglandin E2, PGE2), histamine, bradykinin, and nerve growth factors (NGFs) [56]. The secreted inflammatory mediators increase the expression of sodium and calcium channels, causing peripheral pain sensitization. Inflammatory factors IL- $1 \beta$ and TNF- $\alpha$ can directly stimulate A-fibers and C-fibers to sensitize these and promote abnormal pain and hyperalgesia after nerve injury. Paclitaxel binds to and activates toll-like receptor 4. (TLR4) in monocytes. After 7 days of paclitaxel treatment, TLR4 became elevated in the DRG and became synchronized with the development of mechanical hypersusceptibility induced by the chemotherapy [57].

\section{Chronic pain}

The pain intensity peaked at 3 months after the CRS + HIPEC treatment [58], and this returned to baseline levels after 9 months in $80 \%$ of patients. However, the mechanism for the chronic pain remains unclear. Some studies suggest that nerve injury caused by surgery is a necessary premise for the occurrence of postoperative chronic pain, while the excessive inflammatory response of the nervous system and abnormal immune regulation plays a key role in the progression of postoperative acute pain to chronic pain [19]. At present, no study has investigated the type and mechanism of chronic pain after CRS + HIPEC treatment.

\section{Pain treatment}

In general, the treatment for postoperative pain after CRS + HIPEC treatment includes analgesics and regional nerve blocks (summarized in Table 2). As mentioned above, surgical injuries and chemotherapy agents could cause central and peripheral inflammation after CRS + HIPEC treatment, which could lead to both central and peripheral sensitization, and induce pain [11, 12]. The elevated baseline level of inflammation was also associated with poor prognosis [73]. In a recent meta-analysis, the perioperative use of dexmedetomidine significantly reduced the serum concentrations of IL-6, IL-8, and TNF- $\alpha$ [63]. For surgical patients, a single injection of an induction dose of ketamine was found to reduce the IL6 level for 7 days $[64,65]$. The use of propofol during major surgery could reduce the levels of IL- 6 and IL-8

Table 2 Treatment of postoperative pain

\begin{tabular}{|c|c|}
\hline \multicolumn{2}{|l|}{ Analgesic } \\
\hline $\begin{array}{l}\text { Acetaminophen, NSAIDs, COX-2 } \\
\text { inhibitor [59], gabapentin [60] }\end{array}$ & \multirow{2}{*}{$\begin{array}{l}\text { There was no alleviation of } \\
\text { perioperative inflammation with } \\
\text { the preoperative administration of } \\
\text { celecoxib, tramadol and } \\
\text { pregabalin, and intraoperative TIVA } \\
\text { combined with propofol, } \\
\text { dexmedetomidine, ketamine, and } \\
\text { lidocaine [61]. }\end{array}$} \\
\hline $\begin{array}{l}\text { Propofol [62], dexmedetomidine } \\
\text { [63], ketamine [64,65], and } \\
\text { lidocaine [66] have independent } \\
\text { anti-inflammatory properties. }\end{array}$ & \\
\hline $\begin{array}{l}\text { Calcium channel a-2- } \delta \text { ligand } \\
\text { anticonvulsant drugs, tricyclic an- } \\
\text { tidepressants, selective } 5-\mathrm{HT} \text {, and } \\
\text { norepinephrine reuptake } \\
\text { inhibitors }\end{array}$ & $\begin{array}{l}\text { They provide symptomatic reliefs } \\
\text { and the effects are often limited. }\end{array}$ \\
\hline \multicolumn{2}{|l|}{ Regional nerve block } \\
\hline $\begin{array}{l}\text { TEA combined with opioids has } \\
\text { the advantages of analgesia, } \\
\text { early extubation after surgery, } \\
\text { lower postoperative pulmonary } \\
\text { complications, and reduced } \\
\text { incidence of postoperative } \\
\text { complications [67-70] }\end{array}$ & $\begin{array}{l}\text { TEA is a safe option for CRS }+ \\
\text { HIPEC treatment, regardless of } \\
\text { some fluctuations in intraoperative } \\
\text { coagulation measurements [71, } \\
72] .\end{array}$ \\
\hline
\end{tabular}


[62]. Celecoxib also reduced the prostaglandin E2 level within $48 \mathrm{~h}$ after endoscopic surgery [59]. However, Pascal et al. retrospectively analyzed patients with CRS + HIPEC treatment and found that there was no alleviation of perioperative inflammation with the preoperative administration of celecoxib, tramadol, and pregabalin, and intraoperative TIVA combined with propofol, dexmedetomidine, ketamine, and lidocaine [61].

Conventional analgesic agents (non-steroidal antiinflammatory drugs and opioids) have had little effect in the treatment of NPP. Medications, including calcium channel $\alpha-2-\delta$ ligand anticonvulsant drugs, tricyclic antidepressants, selective 5 -HT and norepinephrine reuptake inhibitors, and local anesthetic drug lidocaine, mainly provide symptomatic relief. These effects are often limited and can have serious side effects.

Although intravenous opioid + thoracic epidural anesthesia (TEA) is the leading choice with many benefits for pain treatment after HIPEC + CRS, the dose of opioids was higher and the duration was longer, when compared to what this was supposed to be in children with HIPEC + CRS [74]. However, this was different from the finding that the duration of opioids was shorter in adults with epidural analgesia [75]. Due to the adverse reactions of opioids (including nausea and constipation), perioperative intravenous lidocaine was used to reduce postoperative pain. However, the systematic analysis conducted by Weibel et al. revealed that it remains uncertain whether perioperative intravenous lidocaine could benefit in decreasing the early postoperative pain score, improving the gastrointestinal recovery, and reducing the postoperative nausea and the consumption of opioids, when compared with placebo or non-treatment [76].

TEA is the "gold standard" for postoperative analgesia in major abdominal surgery [60]. This has also been used for patients who received hyperthermic intrathoracic chemotherapy [77, 78]. Evidence has shown that TEA combined with opioids has the advantages of analgesia, early extubation after surgery, lower postoperative pulmonary complications, and reduced incidence of postoperative complications after CRS + HIPEC treatment [67-70]. Some studies have recommended the use of TEA to reduce the incidence of postoperative intestinal obstruction $[79,80]$. Regional anesthesia also improves tumor recurrence and postoperative survival rates [81-85]. This might also reduce the incidence of chronic pain and improve patient satisfaction [86].

However, there are controversies in the implementation of TEA, since HIPCE could affect blood coagulation and cause thrombocytopenia [68]. A recent prospective clinical study indicated that TEA is a safe option for CRS + HIPEC treatment, regardless of some fluctuations in intraoperative coagulation measurements [71]. Chua et al. investigated 4277 patients who received the CRS +
HIPEC treatment and found no postoperative epidural hematoma in these patients [72]. Due to the difficulty of inserting a catheter, or since traumatic surgery is the main cause of spinal cord hematoma, the preoperative assessment of a patient's history of previous bleeding and medication history is essential and should be performed by an experienced anesthesiologist [68]. A study compared the postoperative analgesic effects of the transversus abdominis plane (TAP) block and TEA in open and laparoscopic colorectal surgery and revealed that TAP infusion was non-inferior [87].

Many factors influence postoperative pain after CRS + HIPEC treatment. The changes in these factors, such as inflammation, oxidative stress, and ion channel, can cause difficulties in providing postoperative analgesia and controlling chronic pain. At present, the management of postoperative acute and chronic pain is mainly from TEA combined with opioids. However, TEA remains challenging and is subject to many factors, such as blood coagulation status. In recent years, the TAP block has gradually been accepted by clinicians $[60,88]$. This blocks the lower thoracic nerves (T7-T12) and the anterior branch of the first lumbar nerve (L1), thereby producing analgesic effects on its branches to the anterior abdominal wall skin, muscle, and parietal peritoneum. The procedure is simple with few complications. Furthermore, this can effectively reduce abdominal incision pain and decrease the requirements for opioids [89]. TAP technology can be considered for the analgesic strategy after CRS + HIPEC treatment.

Some studies have compared the postoperative analgesic effect of TAP with other analgesic methods. Lapmahapaisan et al. compared the effects of the local infiltration of $0.25 \%$ bupivacaine in a wound and TAP block by $0.25 \%$ bupivacaine. It was found that for pediatric patients undergoing massive non-laparoscopic abdominal surgery, a surgically administered TAP (sTAP) block has no distinct advantage over local infiltration and does not induce any effect in postoperative pain control [90]. Deng et al. compared the analgesic effects of the quadratus lumborum block and TAP block after laparoscopic colorectal cancer surgery. The results revealed that the quadratus lumborum block was a more effective method for postoperative analgesia and that this reduced the consumption of sufentanil. However, these literatures were all about major laparoscopic procedures, and the pain was still not comparable to HIPEC + CRS. Considering the advantages of TAP, this is still one of the best choices for CRS + HIPEC surgery [91].

\section{Conclusion}

In summary, both nociceptive and neuropathic processes participate into the development of postoperative pain after CRS + HIPEC treatment in peritoneal cancer. 
Dysregulations of cytokines, nerve cell signaling pathways, and ion channels occur with these peripheral and central pain sensitizations. Conventional analgesics might offer symptomatic relief. Thoracic epidural analgesia and TAP blocks could provide better pain control.

\section{Future perspective}

Since more and more patients are undergoing CRS + HIPEC treatment, it has become a huge challenge for anesthesiologists to determine how to provide effective postoperative analgesia and long-term pain control. Thoracic epidural analgesia has to consider the patient's coagulation function and the anesthesiologist's personal experience and skills, which limits its clinical applications. With the prevalence of ultrasound and the improvement of the skills of nerve blocks in anesthesiologists, the TAP block, which is easier and less traumatic, would replace thoracic epidural analgesia and become a routine postoperative analgesia method [92, 93]. At present, few studies have evaluated the long-term analgesic outcomes of the TAP block. The investigators consider that more research to study the efficacy of TAP blocks on chronic pain are warranted in the future.

\begin{abstract}
Abbreviations
CRS: Cytoreductive surgery; HIPEC: Hyperthermic intraperitoneal chemotherapy; DAMPs: Danger-associated molecular patterns; TNF-a: Tumor necrosis factor-a; IL-6: Interleukin-6; IL-8: Interleukin-8; IL-10: Interleukin-10; IL$1 \beta$ : Interleukin-1 $\beta$; MAPK: Mitogen-activated protein kinase; TLRs: Toll-like receptors; PARP: Poly ADP-ribose polymerase; DRG: Dorsal root ganglion; VGCC: Voltage-gated calcium channels; TRP: Transient receptor potential; ROS: Reactive oxygen species; VGSCs: Voltage-gated sodium channels; VGKCs: Voltage-gated potassium channels; TLR4: Toll-like receptor 4; TIVA: Total intravenous anesthesia; NSAIDs: Non-steroidal anti-inflammatory drugs; TEA: Thoracic epidural anesthesia; TAP: Transversus abdominis plane
\end{abstract}

\section{Acknowledgements}

Not applicable.

\section{Authors' contributions}

XW was the major contributor in writing the manuscript. TL provided the important suggestions for revision. The authors read and approved the final manuscript.

\section{Funding}

Not applicable.

\section{Availability of data and materials}

The datasets used and/or analyzed during the study are available from the corresponding author on reasonable request.

\section{Ethics approval and consent to participate}

Not applicable.

\section{Consent for publication}

Not applicable.

\section{Competing interests}

The authors declare that they have no competing interests.
Received: 3 December 2019 Accepted: 20 March 2020

Published online: 31 March 2020

\section{References}

1. McLaughlin PD, Filippone A, Maher MM. Neoplastic diseases of the peritoneum and mesentery. AJR Am J Roentgenol. 2013;200(5):W420-30.

2. Coccolini F, Gheza F, Lotti M, Virzi S, lusco D, Ghermandi C, et al. Peritoneal carcinomatosis. World J Gastroenterol. 2013;19(41):6979-94.

3. Sugarbaker PH, Ryan DP. Cytoreductive surgery plus hyperthermic perioperative chemotherapy to treat peritoneal metastases from colorectal cancer: standard of care or an experimental approach? Lancet Oncol. 2012; 13(8):e362-9.

4. Gill RS, Al-Adra DP, Nagendran J, Campbell S, Shi X, Haase E, et al. Treatment of gastric cancer with peritoneal carcinomatosis by cytoreductive surgery and HIPEC: a systematic review of survival, mortality, and morbidity. J Surg Oncol. 2011;104(6):692-8.

5. Wang Y, Ren F, Chen P, Liu S, Song Z, Ma X. Effects of CytoReductive surgery plus hyperthermic IntraPEritoneal chemotherapy (HIPEC) versus CytoReductive surgery for ovarian cancer patients: a systematic review and meta-analysis. Eur J Surg Oncol. 2019:45(3):301-9.

6. Tabrizian P, Franssen B, Jibara G, Sweeney R, Sarpel U, Schwartz M, et al. Cytoreductive surgery with or without hyperthermic intraperitoneal chemotherapy in patients with peritoneal hepatocellular carcinoma. J Surg Oncol. 2014;110(7):786-90.

7. Manzanedo I, Pereira F, Perez-Viejo E, Serrano A, Hernandez-Garcia M, Martinez-Torres $B$, et al. Hyperthermic intraoperative intraperitoneal chemotherapy (HIPEC) with primary or secondary cytoreductive surgery in the treatment of advanced epithelial ovarian cancer. Minerva Ginecol. 2017; 69(2):119-27.

8. Pamela K, Matthias Z, Reinhold KR, Julia P, Peter M, Alexander P, et al. Cytoreductive surgery (CRS) and hyperthermic intraperitoneal chemotherapy (HIPEC): a single-center experience in Austria. J Gastrointest Surg. 2018;22(5):884-93.

9. Montori G, Coccolini F, Fugazzola P, Ceresoli M, Tomasoni M, Rubicondo C, et al. Cytoreductive surgery and hyperthermic intraperitoneal chemotherapy in ovarian and gastrointestinal peritoneal carcinomatosis: results from a 7year experience. J Gastrointest Oncol. 2018;9(2):241-53.

10. Said ET, Sztain JF, Abramson WB, Meineke MN, Furnish TJ, Schmidt UH, et al. A dedicated acute pain service is associated with reduced postoperative opioid requirements in patients undergoing cytoreductive surgery with hyperthermic intraperitoneal chemotherapy. Anesth Analg. 2018;127(4): 1044-50.

11. Medina Fernandez FJ, Munoz-Casares FC, Arjona-Sanchez A, Casado-Adam A, Gomez-Luque I, Garcilazo Arismendi DJ, et al. Postoperative time course and utility of inflammatory markers in patients with ovarian peritoneal carcinomatosis treated with neoadjuvant chemotherapy, cytoreductive surgery, and HIPEC. Ann Surg Oncol. 2015;22(4):1332-40.

12. Leijte GP, Custers H, Gerretsen J, Heijne A, Roth J, Vogl T, et al. Increased plasma levels of danger-associated molecular patterns are associated with immune suppression and postoperative infections in patients undergoing cytoreductive surgery and hyperthermic intraperitoneal chemotherapy. Front Immunol. 2018:9:663.

13. Brennan TJ. Pathophysiology of postoperative pain. Pain. 2011;152(3 Suppl): S33-40.

14. Dirks J, Moiniche S, Hilsted KL, Dahl JB. Mechanisms of postoperative pain: clinical indications for a contribution of central neuronal sensitization. Anesthesiology. 2002;97(6):1591-6.

15. Mukherjee P, Cinelli MA, Kang S, Silverman RB. Development of nitric oxide synthase inhibitors for neurodegeneration and neuropathic pain. Chem Soc Rev. 2014;43(19):6814-38.

16. Ogawa N, Kurokawa T, Fujiwara K, Polat OK, Badr H, Takahashi N, et al. Functional and structural divergence in human TRPV1 channel subunits by oxidative cysteine modification. J Biol Chem. 2016;291(8):4197-210.

17. Levinson SR, Luo S, Henry MA. The role of sodium channels in chronic pain. Muscle Nerve. 2012;46(2):155-65.

18. Rao VR, Perez-Neut M, Kaja S, Gentile S. Voltage-gated ion channels in cancer cell proliferation. Cancers (Basel). 2015;7(2):849-75.

19. Chamessian A, Van de Ven T, Buchheit T, Hsia HL, McDuffie M, Gamazon ER, et al. Differential expression of systemic inflammatory mediators in amputees with chronic residual limb pain. Pain. 2017;158(1):68-74. 
20. Woolf CJ. Central sensitization: implications for the diagnosis and treatment of pain. Pain. 2011;152(3 Suppl):S2-15.

21. Costigan M, Scholz J, Woolf CJ. Neuropathic pain: a maladaptive response of the nervous system to damage. Annu Rev Neurosci. 2009;32:1-32.

22. Katz J, McCartney CJ. Current status of preemptive analgesia. Curr Opin Anaesthesiol. 2002;15(4):435-41.

23. Dahl JB, Kehlet H. Preventive analgesia. Curr Opin Anaesthesiol. 2011;24(3): 331-8.

24. Carvalho B, Clark DJ, Angst MS. Local and systemic release of cytokines, nerve growth factor, prostaglandin $E 2$, and substance $P$ in incisional wounds and serum following cesarean delivery. J Pain. 2008;9(7):650-7.

25. Deumens $R$, Steyaert A, Forget $P$, Schubert $M$, Lavand'homme $P$, Hermans $E_{1}$ et al. Prevention of chronic postoperative pain: cellular, molecular, and clinical insights for mechanism-based treatment approaches. Prog Neurobiol. 2013:104:1-37.

26. Ellis $A$, Bennett DL. Neuroinflammation and the generation of neuropathic pain. Br J Anaesth 2013;111(1):26-37.

27. Ko WK, Lee SH, Kim SJ, Jo MJ, Kumar H, Han IB, et al. Anti-inflammatory effects of ursodeoxycholic acid by lipopolysaccharide-stimulated inflammatory responses in RAW 264.7 macrophages. PLoS One. 2017;12(6): e0180673.

28. Thakur KK, Saini J, Mahajan K, Singh D, Jayswal DP, Mishra S, et al. Therapeutic implications of toll-like receptors in peripheral neuropathic pain. Pharmacol Res. 2017;115:224-32.

29. Lim EY, Kim YT. Food-derived natural compounds for pain relief in neuropathic pain. Biomed Res Int. 2016;2016:7917528.

30. Anwar K. Pathophysiology of pain. Dis Mon. 2016;62(9):324-9.

31. Morales-Soriano R, Esteve-Perez N, Segura-Sampedro JJ, Cascales-Campos P, Barrios P. Spanish Group of Peritoneal Malignancy S. Current practice in cytoreductive surgery and HIPEC for metastatic peritoneal disease: Spanish multicentric survey. Eur J Surg Oncol. 2018;44(2):228-36.

32. Ji R-R, Nackley A, Huh Y, Terrando N, Maixner W. Neuroinflammation and central sensitization in chronic and widespread pain. Anesthesiology. 2018; 129(2):343

33. Jaggi AS, Singh N. Mechanisms in cancer-chemotherapeutic drugs-induced peripheral neuropathy. Toxicology. 2012;291(1-3):1-9.

34. Griffiths LA, Flatters SJ. Pharmacological modulation of the mitochondrial electron transport chain in paclitaxel-induced painful peripheral neuropathy. J Pain. 2015;16(10):981-94.

35. Xiao WH, Bennett GJ. Effects of mitochondrial poisons on the neuropathic pain produced by the chemotherapeutic agents, paclitaxel and oxaliplatin. Pain. 2012;153(3):704-9.

36. Farquhar-Smith P. Chemotherapy-induced neuropathic pain. Curr Opin Support Palliat Care. 2011;5(1):1-7.

37. Zheng $\mathrm{H}$, Xiao $\mathrm{WH}$, Bennett GJ. Functional deficits in peripheral nerve mitochondria in rats with paclitaxel- and oxaliplatin-evoked painful peripheral neuropathy. Exp Neurol. 2011;232(2):154-61.

38. Fehrenbacher JC. Chemotherapy-induced peripheral neuropathy. Prog Mol Biol Transl Sci. 2015;131:471-508.

39. Tatsushima Y, Egashira N, Narishige Y, Fukui S, Kawashiri T, Yamauchi Y, et al. Calcium channel blockers reduce oxaliplatin-induced acute neuropathy: a retrospective study of 69 male patients receiving modified FOLFOX6 therapy. Biomed Pharmacother. 2013;67(1):39-42.

40. Carozzi VA, Chiorazzi A, Canta A, Lapidus RG, Slusher BS, Wozniak KM, et al. Glutamate carboxypeptidase inhibition reduces the severity of chemotherapyinduced peripheral neurotoxicity in rat. Neurotox Res. 2010;17(4):380-91.

41. Fonfria E, Murdock PR, Cusdin FS, Benham CD, Kelsell RE, McNulty S. Tissue distribution profiles of the human TRPM cation channel family. J Recept Signal Transduct Res. 2006;26(3):159-78.

42. Caterina MJ, Schumacher MA, Tominaga M, Rosen TA, Levine JD, Julius D. The capsaicin receptor: a heat-activated ion channel in the pain pathway. Nature. 1997;389(6653):816-24

43. Davis JB, Gray J, Gunthorpe MJ, Hatcher JP, Davey PT, Overend P, et al. Vanilloid receptor-1 is essential for inflammatory thermal hyperalgesia. Nature. 2000;405(6783):183-7

44. Ferron G, Gesson-Paute A, Classe JM, Querleu D. Feasibility of laparoscopic peritonectomy followed by intra-peritoneal chemohyperthermia: an experimental study. Gynecol Oncol. 2005;99(2):358-61.

45. Oehler B, Kistner K, Martin C, Schiller J, Mayer R, Mohammadi M, et al. Inflammatory pain control by blocking oxidized phospholipid-mediated TRP channel activation. Sci Rep. 2017;7(1):5447.
46. Obata K, Katsura H, Mizushima T, Yamanaka H, Kobayashi K, Dai Y, et al. TRPA1 induced in sensory neurons contributes to cold hyperalgesia after inflammation and nerve injury. J Clin Invest. 2005;115(9):2393-401.

47. Wu J, Liu TT, Zhou YM, Qiu CY, Ren P, Jiao M, et al. Sensitization of ASIC3 by proteinase-activated receptor 2 signaling contributes to acidosis-induced nociception. J Neuroinflammation. 2017;14(1):150.

48. Srebro D, Vuckovic S, Prostran M. Participation of peripheral TRPV1, TRPV4, TRPA1 and ASIC in a magnesium sulfate-induced local pain model in rat. Neuroscience. 2016;339:1-11.

49. Zhang H, Li Y, de Carvalho-Barbosa M, Kavelaars A, Heijnen CJ, Albrecht PJ, et al. Dorsal root ganglion infiltration by macrophages contributes to paclitaxel chemotherapy-induced peripheral neuropathy. J Pain. 2016;17(7):775-86.

50. Gao R, Shen Y, Cai J, Lei M, Wang Z. Expression of voltage-gated sodium channel alpha subunit in human ovarian cancer. Oncol Rep. 2010;23(5):1293-9.

51. Patel F, Brackenbury WJ. Dual roles of voltage-gated sodium channels in development and cancer. Int J Dev Biol. 2015;59(7-9):357-66.

52. Zhang $H$, Dougherty PM. Enhanced excitability of primary sensory neurons and altered gene expression of neuronal ion channels in dorsal root ganglion in paclitaxel-induced peripheral neuropathy. Anesthesiology. 2014; 120(6):1463-75.

53. Miller C. An overview of the potassium channel family. Genome Biol. 2000; 1(4):REVIEWSO004

54. Tsantoulas C, McMahon SB. Opening paths to novel analgesics: the role of potassium channels in chronic pain. Trends Neurosci. 2014;37(3):146-58.

55. Du X, Gamper N. Potassium channels in peripheral pain pathways: expression, function and therapeutic potential. Curr Neuropharmacol. 2013; 11(6):621-40.

56. Humo M, Lu H, Yalcin I. The molecular neurobiology of chronic paininduced depression. Cell Tissue Res 2019.

57. Li Y, Zhang H, Zhang H, Kosturakis AK, Jawad AB, Dougherty PM. Toll-like receptor 4 signaling contributes to Paclitaxel-induced peripheral neuropathy. J Pain. 2014;15(7):712-25.

58. Albertsmeier M, Hauer A, Niess H, Werner J, Graeb C, Angele MK. Quality of life in peritoneal carcinomatosis: a prospective study in patients undergoing cytoreductive surgery and hyperthermic intraperitoneal chemotherapy (HIPEC). Dig Surg. 2014;31(4-5):334-40.

59. Zhao H, Feng Y, Wang Y, Yang B, Xing Z. Comparison of different loading dose of celecoxib on postoperative anti-inflammation and analgesia in patients undergoing endoscopic nasal surgery-200 mg is equivalent to 400 mg. Pain Med. 2011:12(8):1267-75.

60. Nelson G, Altman AD, Nick A, Meyer LA, Ramirez PT, Achtari C, et al Guidelines for postoperative care in gynecologic/oncology surgery: Enhanced Recovery After Surgery (ERAS(R)) Society recommendations--part II. Gynecol Oncol. 2016;140(2):323-32.

61. Owusu-Agyemang P, Cata JP, Fournier KF, Zavala AM, Soliz J, Hernandez M, et al. Evaluating the impact of total intravenous anesthesia on the clinical outcomes and perioperative NLR and PLR profiles of patients undergoing cytoreductive surgery with hyperthermic intraperitoneal chemotherapy. Ann Surg Oncol. 2016;23(8):2419-29.

62. Corcoran TB, Engel A, Sakamoto H, O'Shea A, O'Callaghan-Enright S, Shorten GD. The effects of propofol on neutrophil function, lipid peroxidation and inflammatory response during elective coronary artery bypass grafting in patients with impaired ventricular function. Br J Anaesth. 2006;97(6):825-31.

63. Li B, Li Y, Tian S, Wang H, Wu H, Zhang A, et al. Anti-inflammatory effects of perioperative dexmedetomidine administered as an adjunct to general anesthesia: a meta-analysis. Sci Rep. 2015;5:12342.

64. Roytblat L, Talmor D, Rachinsky M, Greemberg L, Pekar A, Appelbaum A, et al. Ketamine attenuates the interleukin- 6 response after cardiopulmonary bypass. Anesth Analg. 1998;87(2):266-71.

65. Dale O, Somogyi AA, Li Y, Sullivan T, Shavit Y. Does intraoperative ketamine attenuate inflammatory reactivity following surgery? A systematic review and meta-analysis. Anesth Analg. 2012;115(4):934-43.

66. Yardeni IZ, Beilin B, Mayburd E, Levinson Y, Bessler $H$. The effect of perioperative intravenous lidocaine on postoperative pain and immune function. Anesth Analg. 2009;109(5):1464-9.

67. Piccioni F, Casiraghi C, Fumagalli L, Kusamura S, Baratti D, Deraco M, et al. Epidural analgesia for cytoreductive surgery with peritonectomy and heated intraperitoneal chemotherapy. Int J Surg 2015;16(Pt A):99-106.

68. Raspe C, Piso P, Wiesenack C, Bucher M. Anesthetic management in patients undergoing hyperthermic chemotherapy. Curr Opin Anaesthesiol. 2012;25(3):348-55. 
69. Schmidt C, Creutzenberg M, Piso P, Hobbhahn J, Bucher M. Peri-operative anaesthetic management of cytoreductive surgery with hyperthermic intraperitoneal chemotherapy. Anaesthesia. 2008;63(4):389-95.

70. Liang $Y$, Wang $S$. The best anesthesia regimen for patients undergoing cytoreductive surgery and hyperthermic intraperitoneal chemotherapy. Int J Surg. 2015;19:103.

71. Korakianitis O, Daskalou T, Alevizos L, Stamou K, Mavroudis C, latrou C, et al. Lack of significant intraoperative coagulopathy in patients undergoing cytoreductive surgery and hyperthermic intraperitoneal chemotherapy (HIPEC) indicates that epidural anaesthesia is a safe option. Int J Hyperth. 2015;31(8):857-62.

72. Chua TC, Yan TD, Saxena A, Morris DL. Should the treatment of peritoneal carcinomatosis by cytoreductive surgery and hyperthermic intraperitoneal chemotherapy still be regarded as a highly morbid procedure?: a systematic review of morbidity and mortality. Ann Surg. 2009;249(6):900-7.

73. Kusamura S, Baratti D, Hutanu I, Gavazzi C, Morelli D, lusco DR, et al. The role of baseline inflammatory-based scores and serum tumor markers to risk stratify pseudomyxoma peritonei patients treated with cytoreduction (CRS) and hyperthermic intraperitoneal chemotherapy (HIPEC). Eur J Surg Oncol. 2015;41(8):1097-105.

74. Anghelescu DL, Brown C-L, Murphy AJ, Davidoff AM, Dickson PV, Glazer ES, et al. Anesthesia and pain management for cytoreductive surgery and hyperthermic intraperitoneal chemotherapy for desmoplastic small round cell tumors in children, adolescents, and young adults. Ann Surg Oncol. 2019;26(1):131-8.

75. Osseis M, Weyrech J, Gayat E, Dagois S, Dico RL, Pocard M, et al. Epidural analgesia combined with a comprehensive physiotherapy program after cytoreductive surgery and HIPEC is associated with enhanced postoperative recovery and reduces intensive care unit stay: a retrospective study of 124 patients. European Journal of Surgical Oncology (EJSO). 2016; 42(12):1938-43.

76. Weibel S, Jelting Y, Pace NL, Helf A, Eberhart LH, Hahnenkamp K, et al. Continuous intravenous perioperative lidocaine infusion for postoperative pain and recovery in adults. Cochrane Database Syst Rev. 2018;6.

77. Kerscher C, Ried M, Hofmann HS, Graf BM, Zausig YA. Anaesthetic management of cytoreductive surgery followed by hyperthermic intrathoracic chemotherapy perfusion. J Cardiothorac Surg. 2014;9:125.

78. Joshi GP, Bonnet F, Shah R, Wilkinson RC, Camu F, Fischer B, et al. A systematic review of randomized trials evaluating regional techniques for postthoracotomy analgesia. Anesth Analg. 2008;107(3):1026-40.

79. Webb CA, Weyker PD, Moitra VK, Raker RK. An overview of cytoreductive surgery and hyperthermic intraperitoneal chemoperfusion for the anesthesiologist. Anesth Analg. 2013;116(4):924-31.

80. Arakelian E, Gunningberg L, Larsson J, Norlen K, Mahteme H. Factors influencing early postoperative recovery after cytoreductive surgery and hyperthermic intraperitoneal chemotherapy. Eur J Surg Oncol. 2011;37(10): 897-903.

81. Raspe C, Flother L, Schneider R, Bucher M, Piso P. Best practice for perioperative management of patients with cytoreductive surgery and HIPEC. Eur J Surg Oncol. 2017;43(6):1013-27.

82. Osseis M, Weyrech J, Gayat E, Dagois S, Lo Dico R, Pocard M, et al. Epidura analgesia combined with a comprehensive physiotherapy program after cytoreductive surgery and HIPEC is associated with enhanced postoperative recovery and reduces intensive care unit stay: a retrospective study of 124 patients. Eur J Surg Oncol. 2016;42(12):1938-43.

83. Schmidt C, Steinke T, Moritz S, Bucher M. Thoracic epidural anesthesia in patients with cytoreductive surgery and HIPEC. J Surg Oncol. 2010;102(5): 545-6.

84. Cakmakkaya OS, Kolodzie K, Apfel CC, Pace NL. Anaesthetic techniques for risk of malignant tumour recurrence. Cochrane Database Syst Rev. 2014;11: CD008877.

85. Lorimier G, Seegers V, Coudert M, Dupoiron D, Thibaudeau E, Pouplin L, et al. Prolonged perioperative thoracic epidural analgesia may improve survival after cytoreductive surgery with hyperthermic intraperitoneal chemotherapy for colorectal peritoneal metastases: a comparative study. Eur J Surg Oncol. 2018;44(11):1824-31.

86. Ali M, Winter DC, Hanly AM, O'Hagan C, Keaveny J, Broe P. Prospective, randomized, controlled trial of thoracic epidural or patient-controlled opiate analgesia on perioperative quality of life. Br J Anaesth. 2010;104(3):292-7.

87. Kim AJ, Yong RJ, Urman RD. The role of transversus abdominis plane blocks in enhanced recovery after surgery pathways for open and laparoscopic colorectal surgery. Journal of Laparoendoscopic \& Advanced Surgical Techniques. 2017;27(9):909-14.

88. Rafi AN. Abdominal field block: a new approach via the lumbar triangle. Anaesthesia. 2001;56(10):1024-6.

89. Jakobsson J, Wickerts L, Forsberg S, Ledin G. Transversus abdominal plane (TAP) block for postoperative pain management: a review. F1000Res 2015;4.

90. Lapmahapaisan S, Tantemsapya N, Aroonpruksakul N, Maisat W, Suraseranivongse S. Efficacy of surgical transversus abdominis plane block for postoperative pain relief following abdominal surgery in pediatric patients. Pediatr Anesth. 2015;25(6):614-20.

91. Deng W, Long X, Li M, Li C, Guo L, Xu G, et al. Quadratus lumborum block versus transversus abdominis plane block for postoperative pain management after laparoscopic colorectal surgery: a randomized controlled trial. Medicine. 2019;98(52):e18448.

92. Tsai H-C, Yoshida T, Chuang T-Y, Yang S-F, Chang C-C, Yao H-Y, et al. Transversus abdominis plane block: an updated review of anatomy and techniques. Biomed Res Int. 2017;2017.

93. Pirrera B, Alagna V, Lucchi A, Berti P, Gabbianelli C, Martorelli G, et al. Transversus abdominis plane (TAP) block versus thoracic epidural analgesia (TEA) in laparoscopic colon surgery in the ERAS program. Surg Endosc. 2018;32(1):376-82.

\section{Publisher's Note}

Springer Nature remains neutral with regard to jurisdictional claims in published maps and institutional affiliations.

\section{Ready to submit your research? Choose BMC and benefit from:}

- fast, convenient online submission

- thorough peer review by experienced researchers in your field

- rapid publication on acceptance

- support for research data, including large and complex data types

- gold Open Access which fosters wider collaboration and increased citations

- maximum visibility for your research: over $100 \mathrm{M}$ website views per year

At $\mathrm{BMC}$, research is always in progress.

Learn more biomedcentral.com/submissions 